\title{
Relative Change in SI Engine Performance Using Hydrogen and Alcohol as Fuel Supplements to Gasoline
}

\author{
Jehad A.A. Yamin ${ }^{1 *}$, Eiman Ali Eh Sheet ${ }^{2}$, Khalid S. Rida ${ }^{2}$ \\ 1 Department of Mechanical Engineering, School of Engineering, The University of Jordan, Amman 11942, \\ Jordan \\ 2 Energy and Renewable Energies Technology Center, University of Technology-Iraq, Baghdad 10066, Al Senaa \\ Street, Iraq \\ * Corresponding author's email: yamin@ju.edu.jo
}

\begin{abstract}
A simulation study on the effect of hydrogen and ethanol addition as supplementary fuel for gasoline engine at lean mixture (equivalence ratio $\phi=0.8$ ) was carried out to reduce the gasoline share in the mixture, thus reducing the fuel consumption and harmful emissions. The effect of supplementary fuels on engine performance, emissions, and availability was investigated. This was done by changing the ratio between gasoline and the supplementary fuels in the fuel mixture to achieve the required equivalence ratio. The first part of the simulation consisting of the performance and emissions calculated using the first law, was conducted for all engine speeds. The second part consisting of an availability analysis was conducted at the rated speed of $2750 \mathrm{rpm}$. The simulation study was conducted using the data obtained from measurements of Ricardo E6/T engine parameters (variable compression ratio engine). The data was also used to verify the models. The study shows that the hydrogen addition reduced the carbon monoxide $(\mathrm{CO})$ and nitrogen oxides $\left(\mathrm{NO}_{2}\right)$ share at the lean mixture. The hydrogen addition significantly improved the heat release rate compared with pure gasoline; however, the heat released was close to the top dead center due to its fast burning speed. The ethanol addition improved the first law performance of the engine, e.g., power and efficiency; however, at the cost of increased heat loss. It also improved the indicated work availability in comparison with the addition of hydrogen.
\end{abstract}

Keywords: hydrogen, fuel blend, ethanol, engine availability, engine performance, emissions, lean mixture, entropy.

\section{INTRODUCTION}

The world is consuming its conventional energy sources (mostly fossil) at rapid rates to meet its growing demand. Due to their nature of usage, the consumption of such fossil fuels resulted in environmental problems that have reached an alarming rate. This problem manifested itself in greenhouse gases, depletion of the ozone layer, acid rain, etc. This necessitates the need to find more eco-friendlier energy sources. Several properties possessed by hydrogen made it more preferable to the conventional spark ignition (SI) engine fuels, i.e., gasoline $[1 \div 6]$. Hydrogen has four times the diffusion coefficient of gasoline; this helps better mix and more homogeneity of the fuel mixture $[3,7]$. The adiabatic flame speed of hydrogen is nearly four times higher than that for gasoline; this means more stable engine operation and combustion process closer to constant volume. The flame development and propagation durations are reduced with hydrogen and increase the engine thermal efficiency $[1,2$, 8]. On the other hand, higher adiabatic flame temperature means higher $\mathrm{NO}_{2}$ levels. Furthermore, hydrogen suffers from another severe drawback, i.e., the fuel energy density calculated on a volume basis is much lower than gasoline. This adversely affects the engine out torque. Higher flammability range and lower minimum ignition energy compared with gasoline make the hydrogen-gasoline blend easier to ignite and improve combustion stability under lean conditions. 
Hydrogen as a fuel for internal combustion engines (ICE) has been subjected to significant research. They focused on its use alone and as a supplement to other fuels. Furthermore, some researchers studied the use of hydrogen in spark ignition (SI) and compression ignition (CI) engines $[9 \div 13]$.

An extensive review of hydrogen as a fuel for internal combustion engines is presented in $[14 \div 17]$. The significant advantages and effects on engine performance as well as the main difficulties and problems in implementing hydrogen were also discussed. The effect of various engine parameters at constant speed (variable load) or constant load (variable speed) conditions were studied in the literature. The studies also include the influence of compression ratio (CR), combustion chamber surface/volume $(\mathrm{S} / \mathrm{V})$ ratio, and the boost pressure on engine performance [18]. They reported an increase in engine efficiency and a reduction in $\mathrm{NO}_{2}$ level with a decrease in the $\mathrm{S} / \mathrm{V}$ ratio.

Martinez-Boggio et al. [18] reported an optimum hydrogen/gasoline blending percentage with gasoline (by volume) that prevents cycleto-cycle variations. This percentage is a characteristic of a specific air-fuel ratio. Mohammad Kamil et al. [20] found that the engine output power dropped less than $6 \%$ for a $10 \%$ hydrogen addition to gasoline. Salahaddin et al. [21] reported that the addition of ethanol to gasoline ( $20 \%$ by volume) did not improve the engine performance. However, the combustion process, its efficiency (defined as the amount of fuel energy supplied to the control volume around the engine which can be released by combustion), and stability (defined as that the variations of the combustion process from cycle to cycle) improved with hydrogen addition to the gasolineethanol blend. On the other hand, it caused the $\mathrm{NO}_{X}$ emissions to increase.

D'Andrea et al. [22] studied the influence of hydrogen blended with gasoline at different engine speeds and for the range of equivalence ratios on the combustion process. They reported lower cyclic variations and decreased combustion durations with hydrogen addition. Iodice et al. [23] showed that the addition of ethanol to gasoline resulted in reduced cold emissions. Phuangwongtrakul et al. [24] also showed improvements in engine torque and efficiency with ethanol and gasoline in the SI engine. Varde [25] studied the engine operational stability using hydrogen-gasoline bends. He found that the combustion durations were reduced with the extension on lean burn limits with hydrogen addition.

Dimopoulos et al. [26] also proved that with the help of hydrogen injection, pilot fuel greenhouse emissions could be reduced. Other researchers $[27,28]$ showed improvements in engine thermal efficiency and emissions except for the $\mathrm{HC}$ and $\mathrm{CO}$ emissions at around 5\% hydrogen volume fraction. Several studies $[29 \div 38]$ showed a reduction in some regulate emissions, e.g., carbon monoxide (CO), total hydrocarbons (THC), and carbon dioxide $\left(\mathrm{CO}_{2}\right)$ with ethanol addition. On the other hand, no significant trends were reported in these studies regarding the $\mathrm{NO}_{2}$ emissions connected with ethanol addition. The major disadvantage reported as a result of ethanol addition is that it leads to an increase in the formaldehyde and acetaldehyde emissions.

As far as the second law analysis is concerned, Hakan Ozcan [39] conducted a theoretical analysis of hydrogen as supplement fuel for $\mathrm{CNG}$ for SI engine fueling. He concluded that the hydrogen addition had a noticeable effect on engine availability (It is defined as the maximum work that can be produced from the system through the interaction with its surroundings during a reversible transition to a state of thermal, mechanical, and chemical equilibrium with its environment, which is defined as the dead state of the system). Combustion irreversibilities decreased while the thermal efficiency, calculated using the second law model, increased with hydrogen addition. Rakopoulos and Kyritsis $[40,41]$ studied the effect of hydrogen enrichment on the second law performance of an engine powered with natural gas and landfill gas. They also reported a reduction in combustion irreversibility and, as a consequence, an improvement in "second law efficiency" with increasing proportions of hydrogen.

The main objective of this research was to investigate the effect of adding hydrogen and ethanol to gasoline on the SI engine performance from the first and second law point of view. The experiment was conducted for the lean air/fuel mixture $(\phi=0.8)$.

\section{Fuel Properties}

Table 1 shows some of the significant properties of hydrogen and ethanol as fuels for SI 
Table 1. Properties of fuels $[31 \div 35]$

\begin{tabular}{|l|c|c|c|}
\hline \multicolumn{1}{|c|}{ Property } & Gasoline & Hydrogen & Ethanol \\
\hline Density at 1 atm and 300 K $\left(\mathrm{kg} / \mathrm{m}^{3}\right)$ & $720-760$ & 0.082 & 796 \\
\hline Stoichiometric A/F ratio (by volume) & 59.5 & 2.39 & 14.28 \\
\hline Research octane number & $90-100$ & 130 & 108 \\
\hline Lower heating value $(\mathrm{MJ} / \mathrm{kg})$ & 43.448 & 119.7 & 26.952 \\
\hline Thermal conductivity at 300 K (mW/m K) & 11.2 & 182.0 & 171 \\
\hline Diffusion coefficient into air at NTP $\left(\mathrm{cm}^{2} / \mathrm{s}\right)$ & 0.05 & 0.61 & 0.115 \\
\hline Flammability limits $(\%$ Volume) & $1.2-6.0$ & $4-75$ & $4.3-19$ \\
\hline Minimum ignition energy $(\mathrm{mJ})$ & 0.25 & 0.02 & 0.23 \\
\hline Laminar flame speed at NTP $(\mathrm{m} / \mathrm{s})$ & $0.37-0.43$ & $\sim 2.0$ & 0.62 \\
\hline Adiabatic flame temperature $\left({ }^{\circ} \mathrm{C}\right)$ in air & $\sim 2470$ & 2318 & 2082 \\
\hline
\end{tabular}

engines. For stoichiometric combustion, hydrogen needs (on a volume basis) the least amount of the air (2.39 moles) compared to 14.28 moles for ethanol and 59.6 moles for gasoline. On the other hand, on a mass basis, it needs the highest amount of the air for stoichiometric combustion $(34 \mathrm{~kg}$ ) for hydrogen compared with $8.95 \mathrm{~kg}$ for ethanol and $14.7 \mathrm{~kg}$ for gasoline). It has the highest calorific value on a mass basis (lowest value on a volume basis). It means the highest energy, which could be released during stoichiometric combustion.

Hydrogen has the highest octane number amongst other fuels, which contributes to its excellent knock resistance. It has excellent diffusive and heat transfer characteristics. Hydrogen has the widest flammability limits, which enables it to burn leaner air/fuel mixtures and hence improves the engine fuel economy. The lower minimum energy value needed for ignition makes it burn faster and better than other fuels. It may be concluded that all three fuels have significantly different combustion properties.

The majority of IC engines are designed and optimized for gasoline (or Iso-Octan) as the prime fuel. The use of any other fuel or fuel blends sometimes demands changing its construction and practically always regulating a fuel system. The engine adaptation allows mitigating some problems, e.g., excessive rate of pressure rise (as a result of speedy combustion process) or premature completion of the combustion process near the top dead center (TDC).

One way of proper utilization of the supplementary fuel is to understand how it affects the engine operation. Most of the above-presented research focuses on the alternatively fueled engine parameters, and the engine cycle is analyzed using the first thermodynamics law. This study combines both the first and second law analysis to calculate engine parameters for fueling with two alternative fuels as supplement fuel to gasoline at lean operation.

The engine examination aimed to analyze the engine thermal efficiency for gasoline fuelling and compared it to the proposed engine fueling methods with two fuel blends (hydrogen/gasoline and ethanol/gasoline). The equivalence ratio selected for this study was $\phi=0.8$. This regulation enables us to obtain lower $\mathrm{NO}_{2}$ and $\mathrm{CO}_{2}$ emissions than for richer mixtures. The study will be continued for lean mixtures to extend the lean limit of the engine run as well as to reduce fuel consumption and engine emissions.

\section{The Engine}

The engine used for this study to verify the mathematical model was the Ricardo E6/T, 4-stroke, water-cooled variable stroke (or compression ratio) engine. The model is well verified for this engine and has been tested for other fuels and variables. The basic engine specifications are shown below in Table 2 .

Table 2. Engine specification

\begin{tabular}{|l|c|}
\hline Engine parameter & Value \\
\hline Type & $\begin{array}{c}\text { Ricardo E6/T variable } \\
\text { compression ratio }\end{array}$ \\
\hline Bore $\times$ stroke & $76.2 \times 111.125 \mathrm{~mm}$ \\
\hline Displacement volume & $504 \mathrm{~cm}^{3}$ \\
\hline Engine speed & Variable \\
\hline Compression ratio & $8: 1$ (fixed) \\
\hline Spark advance & $20^{\circ}$ bTDC \\
\hline Throttle position & Wide open (WOT) \\
\hline
\end{tabular}




\section{Theoretical analysis}

A two-zone internal combustion engine model, mainly described in $[6,26]$ and their relative modifications, was used in this work. This model treats the combustion chamber to consist of two distinct zones (e.g., burned and unburned) separated by the flame front. The main equations applied to analyze those zones are the first law of thermodynamics and the continuity equation. These equations are derived with respect to the crank angle $(\theta)$ to yield several coupled first-order differential equations for pressure, volume, temperature (burned and unburned), mass, heat flux, etc. that are applied for both zones. Derivation of the equation of state with respect to $\theta$ gives:

$$
\begin{gathered}
\frac{d P}{d \theta}=\frac{\left[-\left(1+\frac{R}{C_{v}}\right) \cdot P \cdot \frac{d V}{d \theta}-\frac{R d Q_{C r}}{C_{v} d \theta}+\frac{R d Q_{h t}}{C_{v} d \theta}\right]}{V} \\
\frac{d T}{d \theta}=T \cdot\left(\frac{1}{P} \frac{d P}{d \theta}+\frac{1}{V} \frac{d V}{d \theta}\right)
\end{gathered}
$$

where: $P$ is the cylinder pressure $[\mathrm{kPa}], T$ is the cylinder temperature $[\mathrm{K}], \theta$ is the crank angle [degree], $V$ is the cylinder volume $\left[\mathrm{m}^{3}\right]$ which is a function of crank angle rotation, $R$ is the gas constant $[\mathrm{kJ} / \mathrm{kg}-\mathrm{K}], C_{V}$ is the specific heat at constant volume $[\mathrm{kJ} / \mathrm{kg}-\mathrm{K}], Q_{c r}$ is the total heat flux lost to crevice (or with blow-by), and $Q_{h t}$ is the total heat flux lost to coolant [kW].

As for the cylinder pressure, it is usually assumed to be uniform throughout the cylinder charge. The instantaneous cylinder volume $V(\theta)$ measured from bottom dead center (BDC) position can be expressed using the cylinder mechanism (a slider-crank mechanism) with certain modifications as:

$$
V(\theta)=V_{S}\left[\left(\frac{C R}{C R-1}\right)-\left(\frac{1-\cos (\theta)}{2}\right)+\left(\frac{C R L}{S}\right)-\frac{1}{2} \sqrt{\left(\frac{2 \cdot C R L}{S}\right)^{2}-\sin ^{2}(\theta)}\right]
$$

where: $C R$ is the compression ratio [dimensionless], $C R L$ is the connecting rod length [m], $S$ is the stroke length $[\mathrm{m}]$, and $V_{S}$ is the stroke volume $\left[\mathrm{m}^{3}\right]$.

Derivation of equation (3) with respect to $\theta$ gives the rate of change of cylinder volume with crank angle as follows:

$$
\frac{d V}{d \theta}=\frac{1}{2} V_{S} \sin \theta\left(\frac{\cos \theta}{\sqrt{\left(\frac{2 C R L}{S}\right)^{2}-\sin ^{2} \theta}}-1\right)
$$

This helps calculate the rate of change of indicated work $W$ with crank angle:

$$
\frac{d W}{d \theta}=P \frac{d V}{d \theta}
$$

Moreover, the heat lost during the cycle $Q_{h t}$ is used as follows:

$$
\frac{d Q_{h t}}{d \theta}=\frac{h_{w}}{\omega} A_{w}(\theta)\left[\left(T-T_{w}\right)\right]
$$

where: $A_{W}$ is the cylinder wall surface area $\left[\mathrm{m}^{2}\right], T_{W}$ is the cylinder wall temperature $[\mathrm{K}]$ and $\omega$ is the angular velocity $\left[\mathrm{s}^{-1}\right]$, and $h_{W}$ is the convective heat transfer coefficient $\left[\mathrm{W} / \mathrm{m}^{2}-\mathrm{K}\right]$.

The formula used for the calculation of the heat transfer coefficient $h_{W}$ from cylinder contents to walls is shown below in equation (7).

$$
h_{w}=\frac{\mathrm{P}^{0.8} \mathrm{v}^{0.8}}{\mathrm{~T}^{0.53} \mathrm{D}^{0.2}}
$$

where: the value of the gas velocity $v$ is taken to be equal to $6.18 \cdot v_{m}$ during scavenging and intake stroke $(\mathrm{m} / \mathrm{s})$; and during the compression stroke, it takes the value equal to $2.28 \cdot V_{m}$. During the remaining four strokes, the value used for the gas velocity is $v=2.28 v_{m}+0.00324\left(V_{S} T_{a}\right) /$ $\left(P_{a} V_{a}\right) \cdot\left(P-P_{\text {motored }}\right)$.

The mean gas velocity $V_{m}$ is given by $V_{m}=2 S \cdot N / 60 . P_{a}, T_{a}, V_{a}$ are pressure, temperature, and volume of the cylinder at the beginning of compression, respectively; and, $P_{\text {motored }}$ is the cylinder pressure during motoring (no combustion) (Pa). As for the energy flow through the crevice, Gatowski et al. (1984) expression for a spark-ignition engine was used. This is shown below in equation (8). 


$$
\frac{d Q_{c r}}{d \theta}=(u+R \cdot T) \cdot \frac{d m_{c r}}{d \theta}
$$

where: $u$ is the internal energy in $(\mathrm{kJ} / \mathrm{kg}), m_{c r}$ is the mass flow through the crevice in $(\mathrm{kg}), d m_{c r}>0$ for the case of flow into the crevice, $d m_{c r}<0$ for the case of flow out-of-crevice, $(u+R \cdot T)$ is calculated based on engine cylinder conditions when $d m_{c r}>0$ and under crevice conditions when $d m_{c r}<0$.

Further, Wiebe function Eq. (1) [41] was used to model the mass fraction burned $\left(\chi_{b}\right)$ vs. crank angle (CA).

$$
x_{b}=\frac{m_{b}}{m_{\text {mix }}}=1-e^{\left[-a\left(\frac{\theta-\theta_{o}}{\Delta \theta_{b}}\right)^{m+1}\right]}
$$

where: $m_{b}$ is the mass fraction burned and $m_{\text {mix }}$ is the total mass of the fuel inside the cylinder $[\mathrm{kg}], \theta_{O}$ is the start of combustion [deg], $\Delta \theta_{b}$ is the burning duration [deg], and $a$ and $m$ are model constants.

The derivative of the mass fraction burned as a function of crank angle is given by:

$$
\frac{d x_{b}}{d \theta}=\left(a \frac{m+1}{\Delta \theta_{b}}\right)\left(\frac{\theta-\theta_{o}}{\Delta \theta_{b}}\right)^{m} e^{\left[-a\left(\frac{\theta-\theta_{o}}{\Delta \theta_{b}}\right)^{m+1}\right]}
$$

The rate of work availability $A_{W}$ is given by:

$$
\frac{d A_{w}}{d \theta}=\left(P-P_{o}\right) \frac{d V}{d \theta}
$$

where: $P_{O}$ is the dead state pressure (usually the atmospheric pressure $[\mathrm{kPa}]$.

The expression for the rate of availability transfer due to irreversible heat transfer $A_{L}$ is given by:

$$
\frac{d A_{L}}{d \theta}=\left(1-\frac{T_{o}}{T}\right) \frac{d Q_{h t}}{d \theta}
$$

where: $T_{O}$ is the dead state temperature (or the atmospheric temperature) $[\mathrm{K}]$.

The rate of fuel availability $A_{f}$ into the process:

$$
\frac{d A_{f}}{d \theta}=(1-x)\left(\frac{d x_{b}}{d \theta}\right) a_{f}
$$

$$
a_{f}=L H V_{f}\left[1.0334+0.0183 \frac{H}{C}-0.0694 \frac{1}{C}\right](13.1)
$$

For the closed part of the cycle in an engine, the exergy efficiency is shown as follows:

$$
\eta_{\text {exergy }}=\frac{W_{\text {net }}}{E x_{\text {fuel }}}
$$

A detailed presentation of the second law analysis of engine combustion was provided in $[43 \div 47]$. In this study, the mixture was varied, keeping the overall trapped equivalence ratio $=$ 0.8. This was done for both fuels. The ignition timing was kept constant at 20 degrees bTDC as in the engine design. Since the main aim of the research was to keep the fossil fuel used (i.e., gasoline) on a minimum level, the gasoline flow rate was adjusted to keep a constant equivalence ratio $(\phi=0.8)$. The first engine simulation was run for $\phi=0.8$ with the use of gasoline only. The first calculation enabled to set gasoline dose and a reference engine performance. The gasolinehydrogen mixture was then created by adjusting (reducing) gasoline mass flow to remain equivalence ratio $(\phi=0.8)$.

\section{RESULTS}

The simulation results show the engine performance and emissions, but the result discussion also includes the exergy analysis of the SI engine to maximize the work availability.

\section{Brake Power}

Figure 1 shows engine brake power (BP) for ethanol/gasoline and hydrogen/gasoline blends $(\phi=0.8)$. It can be seen from Figure 1 that BP increases with the addition of both hydrogen and ethanol fuels. The influence of ethanol on brake power is more visible than in the case of hydrogen. Several researchers reported an increase of the engine brake power with the addition of ethanol, e.g. $[48 \div 50]$.

In order to understand this trend, Figures 2, 3,4 , and 5 show the energy flow into the cylinder for all fuel blends, the indicator diagrams calculated for the engine rated power speed,

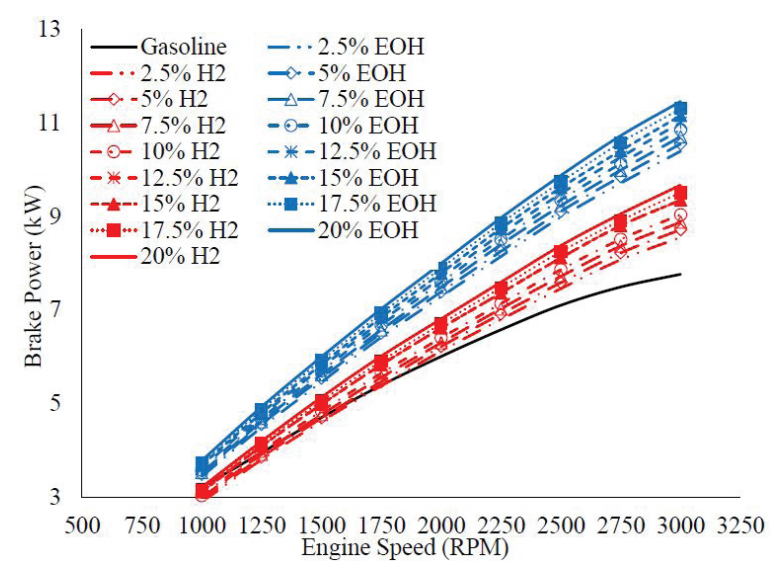

Fig. 1. Brake power variation with engine speed for all fuel blends 


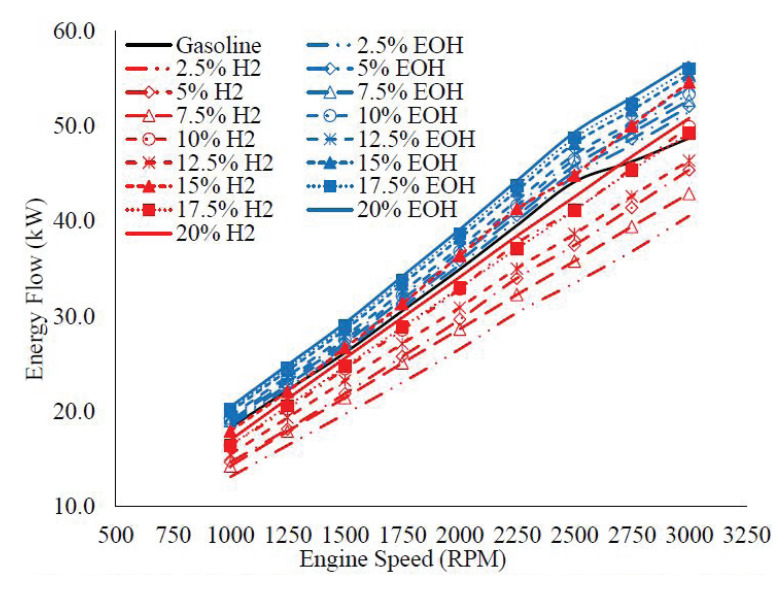

Fig. 2. Energy flow into the engine variation with engine speed for all fuel blends

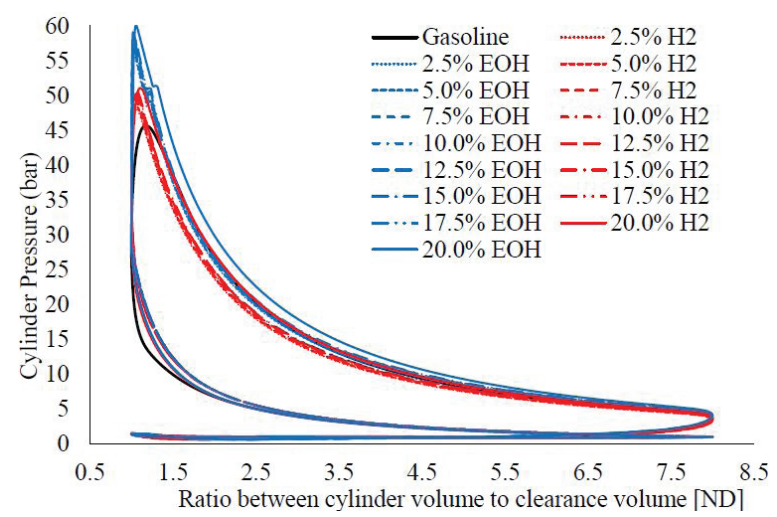

Fig. 3. Indicator diagrams comparision at $2750 \mathrm{RPM}$

i.e., $2750 \mathrm{rpm}$ and ignition timing 20-degree bTDC) and peak cylinder pressure for both fuels. It can be seen that the energy flow (shown in Figure 2) for both fuel blends increases with the percentage of supplement fuel in the mixture. Furthermore, the amount of energy in the mixture is higher for ethanol/gasoline blend compared with the hydrogen/gasoline blends. In addition, the peak cylinder pressure for both fuels increases with their respective percentage in the mixture. However, this peak pressure occurs close to TDC with higher pressures for ethanol than hydrogen, as shown in Figures 3, 4 and 5. In his review article, Mohammad et al. [52] explained this pressure rise due to the higher volumetric efficiency and lower intake temperatures with ethanol/gasoline blend. There are many reasons for this phenomenon, starting from the mixture energy content flowing into the cylinder, hydrogen properties, and the effect of constant spark timing $[1,2]$.

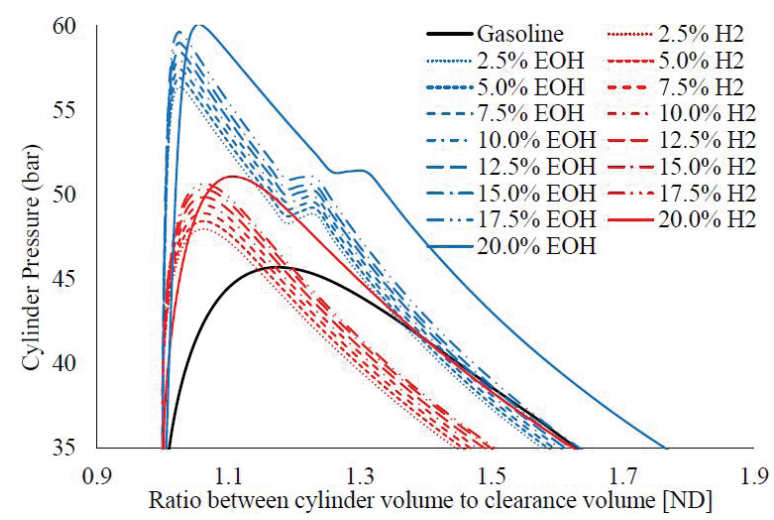

Fig. 4. Peak pressure comparison for all fuel blends at 2750 RPM

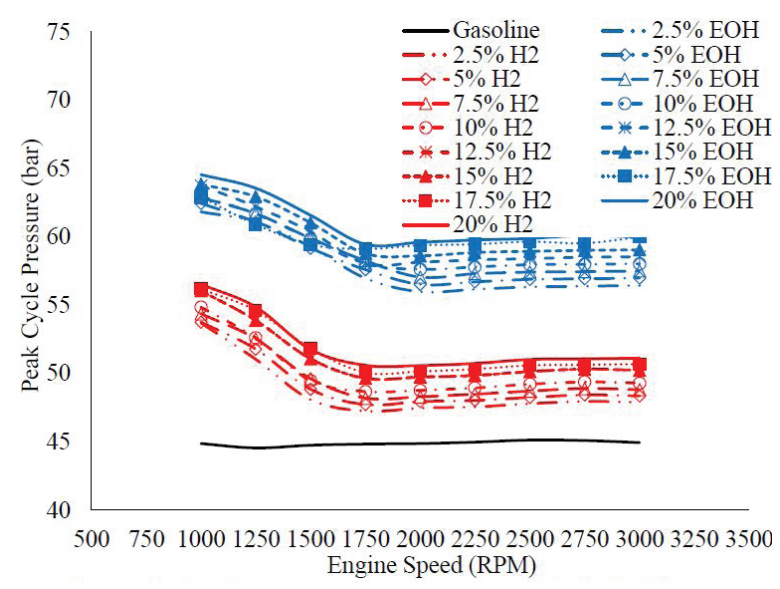

Fig. 5. Peak cylinder pressure vs. engine speed for all fuel blends

Hydrogen tends to decrease the energy content of a cylinder due to lower energy content on a volume basis. In addition, the drop in volumetric efficiency is caused by the heating effect of the inlet manifold, which causes the gaseous fuel to expand. This effect is the opposite of ethanol, which tends to cool the inlet manifold due to its evaporation.

\section{Brake Thermal Efficiency}

Thermal efficiency is an important parameter showing how effectively the engine utilizes the energy supplied to it with the fuel to useful work. It can be said that Thermal efficiency is inversely proportional to the engine fuel economy (specific fuel consumption) for the same fuel. As the thermal efficiency of the engine increases, the engine could develop more power for the same amount of fuel. Hence, this factor should be maximized. The relative change in brake thermal efficiency 


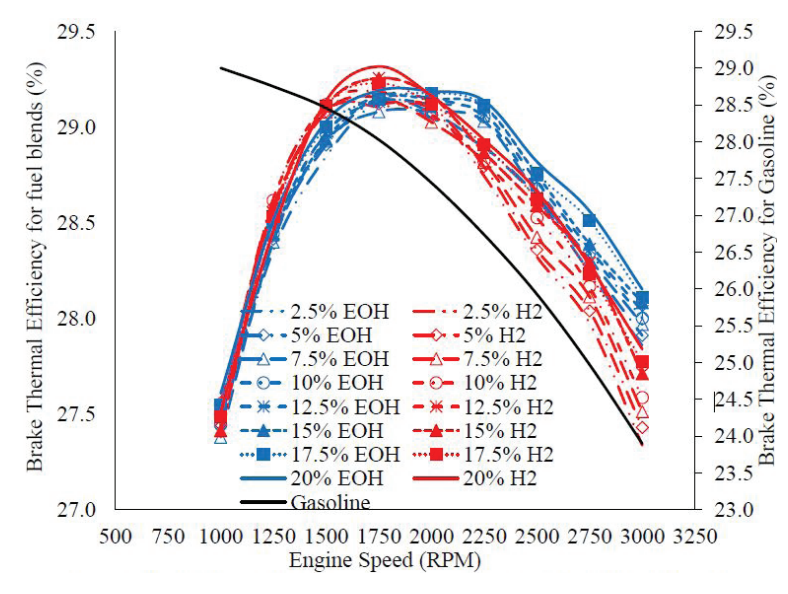

Fig. 6. Brake thermal efficiency vs. engine speed for all fuel blends

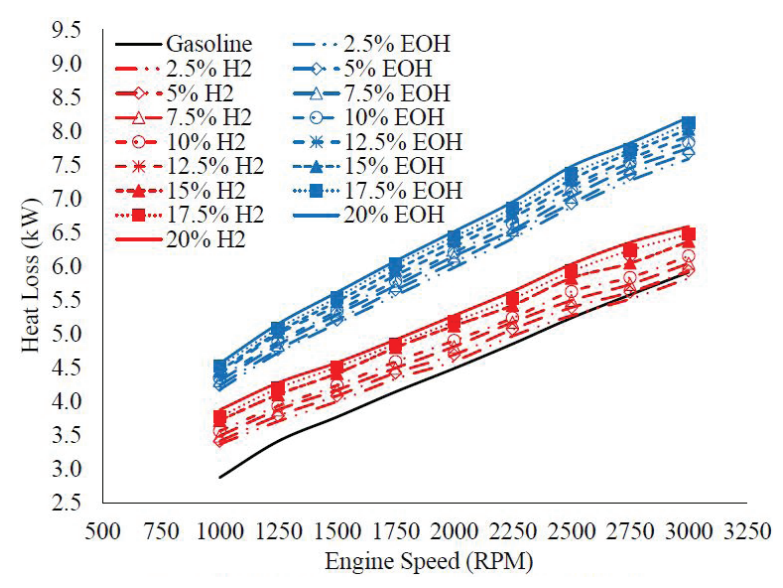

Fig. 7. Heat loss vs. engine speed for all fuel blends

with an engine speed for both fuels is shown in Figure 6. As shown in Figure 6, the brake thermal efficiencies of the hydrogen-enriched mixtures are higher than those with ethanol addition, especially at higher fuel fraction. Moreover, at lower engine speeds, the engine fueled thermal efficiency with both fuel blends is less than that for gasoline.

Deng et al. [51] explained that this is because of the hydroxyl radical (-OH) produced from ethanol, which improves the combustion and flame propagation speed. However, due to the increased amount of fuel in the engine due to the lower calorific value, the energy input rises, and the consequent heat loss increases. Figure 6 shows the percentage of heat loss for ethanol/gasoline blend compared with hydrogen addition to gasoline. For both fuels, the heat loss increases for the mixtures with additional fuels. Furthermore, the heat loss with ethanol/gasoline blends is higher than those for hydrogen/gasoline mixtures. One possible reason for this phenomenon is the shorter duration of combustion with hydrogen addition due to faster flame speed; hence, less time will be available for the combustion products to lose their energy.

\section{Heat Release Rate (HRR)}

Several factors influence the thermal efficiency of an engine: heat loss, combustion time, combustion process (e.g., flame development, duration, and propagation). Figure 8 shows the HRR for all analyzed cases at all engine speeds. As shown in the figure, the heat release rate for both blends is more significant than that for pure gasoline. The figure also shows that the RoHR for the ethanol/gasoline blend is higher than that with hydrogen. The difference between the maximum peak of RoHR for both blends is about $20 \%$, favoring the ethanol/gasoline blend. It was expected due to the higher energy content for the ethanol/gasoline mixture than for hydrogen/gasoline. Further noticed that the angular position of the peak of RoHR shifts more with ethanol added to the mixture and that the effect of ethanol addition is more significant for the case of hydrogen. This can be attributed to the formation of $\mathrm{OH}$ radicals in the cylinder, which improves the chain branch reactions and reduces the flame development period $[1,2]$.

\section{Engine emissions}

From the engine emissions point of view, the addition of $\mathrm{H}_{2}$ helped to reduce the $\mathrm{CO}$ emission

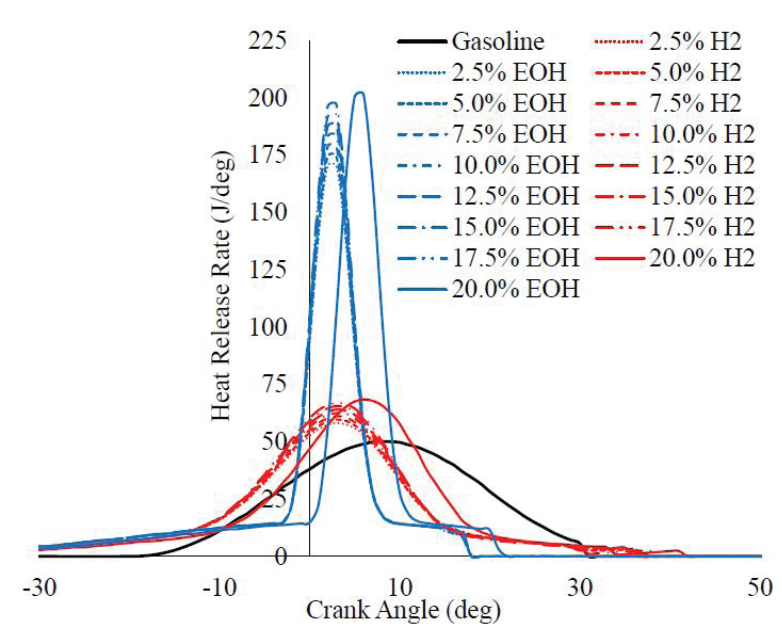

Fig. 8. The comparisson of the heat release rate for all fuel blends 


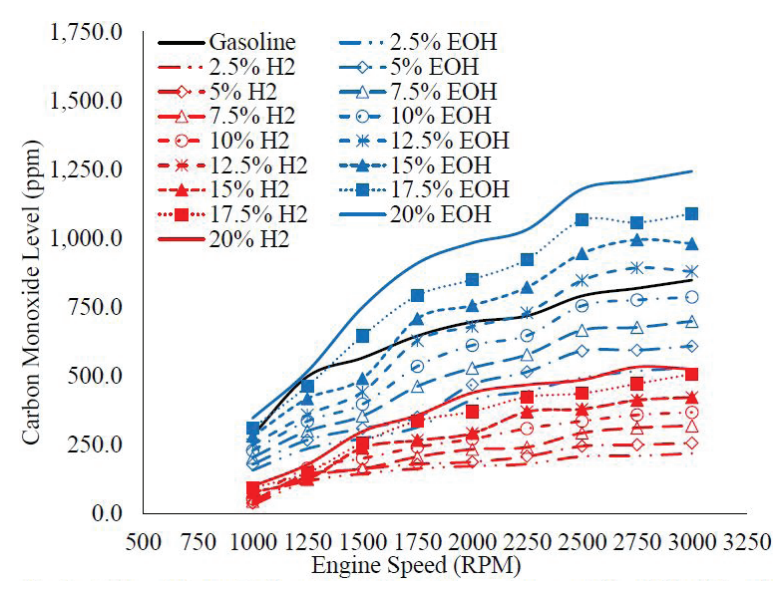

Fig. 9. Carbon monoxide level variation with engine speed for all fuel blends

to a greater extent than ethanol. This is shown below in Figure 9. One key factor affecting the reduction of $\mathrm{CO}$ formation is the availability of oxygen. Hydrogen enlarges this phenomenon more than ethanol. By adding more hydrogen fuel to the mixture (and reducing gasoline fraction to maintain the equivalence ratio), more oxygen is available, and less carbon is burnt inside the cylinder compared with the addition of ethanol, reducing the carbon-related emissions. Two more factors play an essential role in the increased $\mathrm{CO}$ emissions reduction with hydrogen, compared with ethanol. First; the reduction of the overall $\mathrm{H} / \mathrm{C}$ as explained above, and second is the improvement in the combustion efficiency with hydrogen addition. Concerning Table 1, it can be noticed that the flame speed and the diffusion coefficient for hydrogen are higher than for both other fuels (gasoline and ethanol). These factors help to improve the oxidation process of carbon. Similar results were also reported by [46, 47].

Several factors affect the formation of $\mathrm{NO}_{X}$ emissions inside the cylinder, e.g., combustion temperature, oxygen availability, combustion time, etc. It is noticed from Figures 2 and 3 that the cylinder temperature (and indirectly pressure) increases with the addition of the hydrogen and ethanol to the air-fuel mixture. This ultimately resulted in an increased share of $\mathrm{NO}_{X}$ in exhaust gases, as shown in Figure 10. From the kinetics point of view, $\mathrm{NO}_{X}$ is primarily formed from $\mathrm{NO}$ radical and less from $\mathrm{NO}_{2}$. Nitrogen oxide exists mainly in the flame zone during combustion, and it is then converted to $\mathrm{NO}_{2}$ as shown in the following reaction:

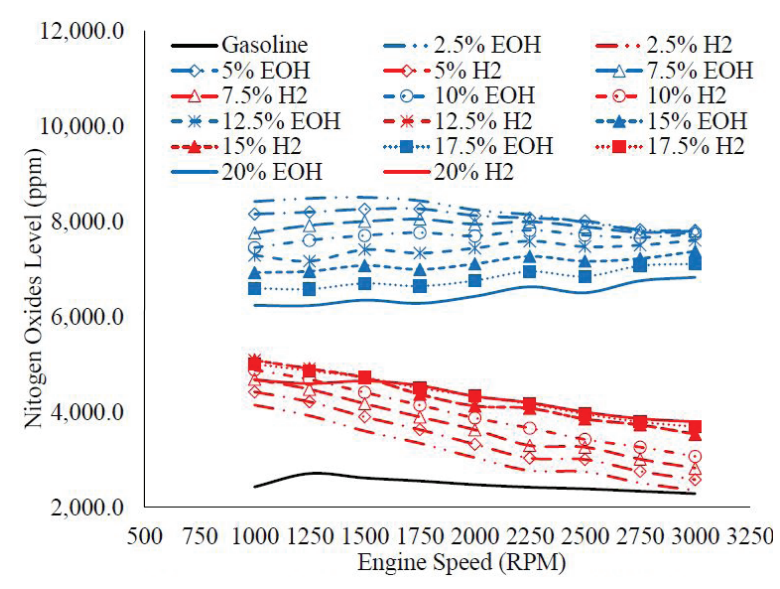

Fig. 10. Nitrogen oxides level vs. engine speed for all fuel blends

$$
\mathrm{NO}+\mathrm{HO}_{2} \leftrightarrow \mathrm{NO}_{2}+\mathrm{OH}
$$

However, due to the negative activation energy and low levels of $\mathrm{HO}_{2}$, the $\mathrm{NO}_{2}$ formation is prompt.

With hydrogen addition, the formation of NO tends to reduce due to the third body reaction shown below:

$$
\mathrm{H}+\mathrm{O}_{2}+\mathrm{M} \leftrightarrow \mathrm{HO}_{2}+\mathrm{M}
$$

This causes an increase in the concentration of $\mathrm{HO}_{2}$ radicals [4]. It is also seen from Figure 10 that the maximum $\mathrm{NO}_{X}$ emissions are reached for $17.5 \%$ hydrogen and $2.5 \%$ ethanol. Beyond this value, the increment rate is slower. With the increased fraction of the supplement fuel in the mixture, hydrogen needs more air to be burnt. The higher cylinder pressure and a higher temperature are observed in a cycle. One reason for this phenomenon is the phase difference between gasoline and hydrogen, which causes a certain

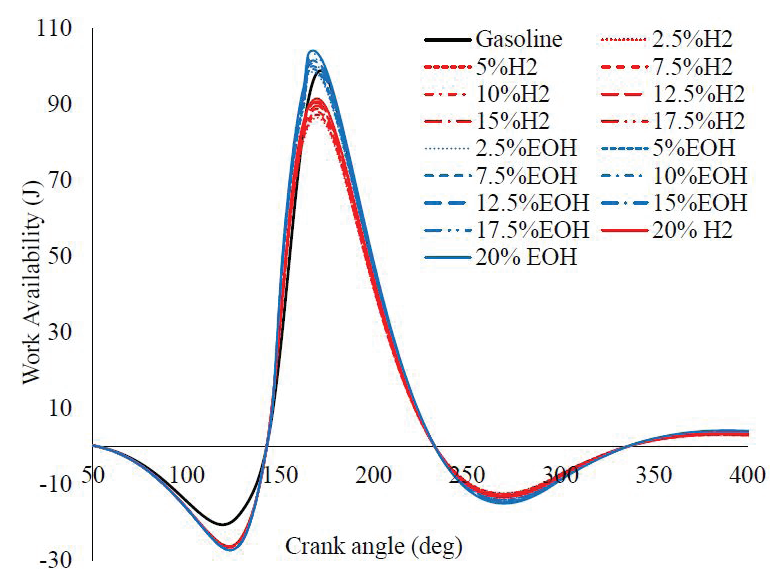

Fig. 11. Work availability 


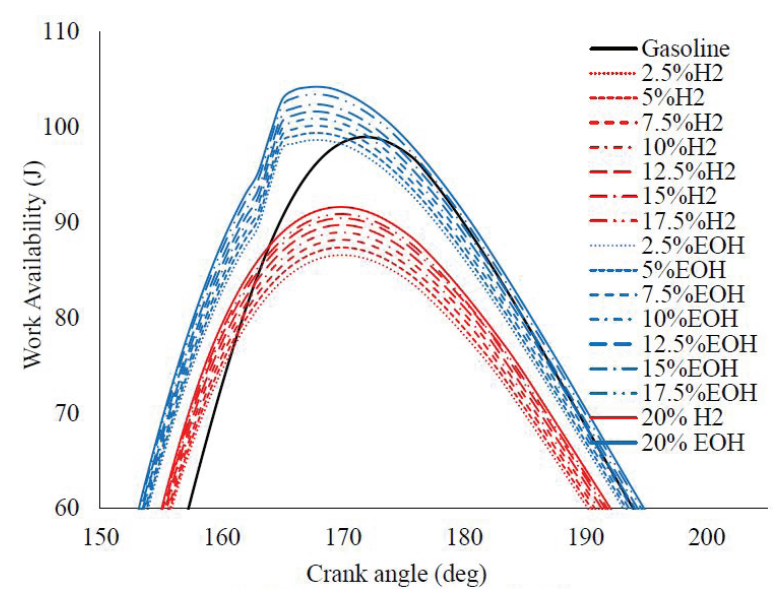

Fig. 12. Maximum work availability

degree of the mixture inhomogeneity. It requires supplying a higher amount of air to help to burn these extra hydrogen supplements.

\section{Engine Availability Analysis}

The second law analysis shows that the mixture exergy is larger for the ethanol fuel addition than for hydrogen (Figures 11 and 12). Furthermore, Figure 11 shows that for both fuels, the exergy transferred with work inside the cylinder is higher than that for pure gasoline. This trend helps explain why the engine tends to develop more power when fueling with ethanol/gasoline blends at the fixed equivalence ratio for fixed ignition timing than with hydrogen. In addition, Figure 12 shows that the amount of exergy availability inside the cylinder is more with ethanol/gasoline blend compared with hydrogen/gasoline. This helps explain the

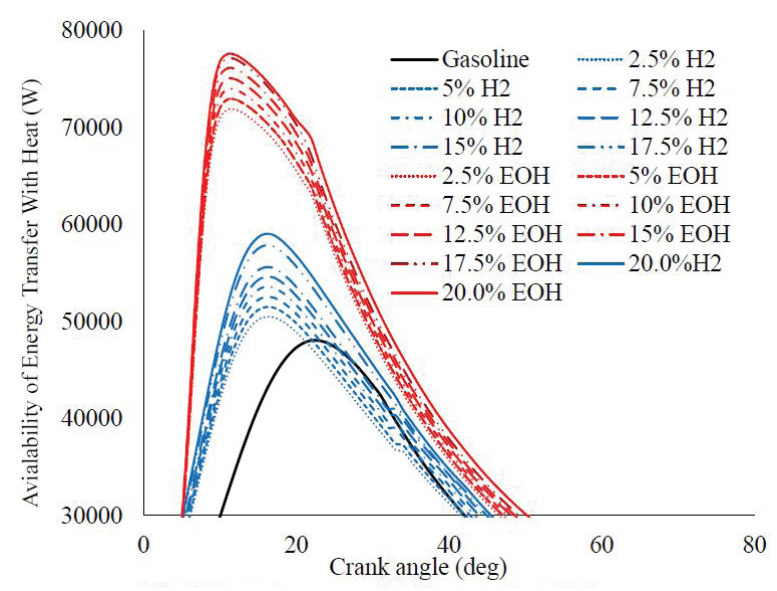

Fig. 14. Maximum availability transfer with heat

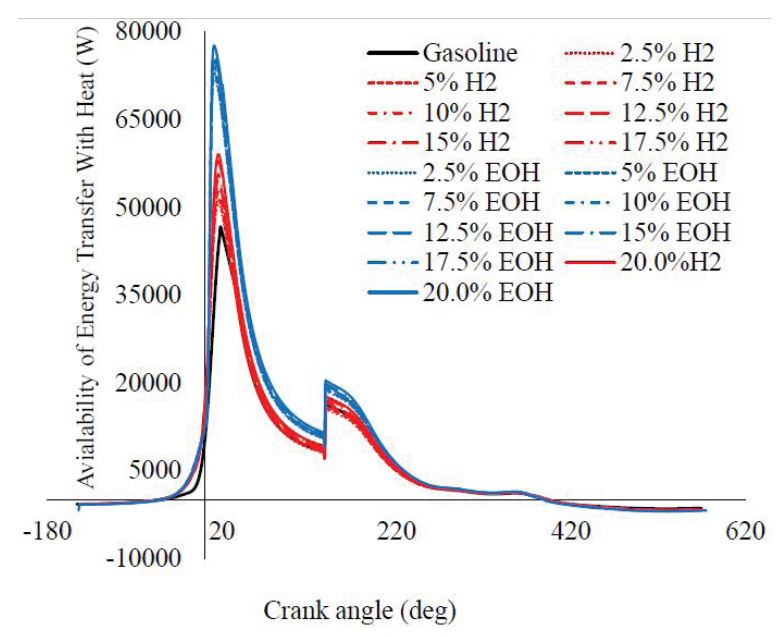

Fig. 13. Availability transfer with heat

above-mentioned first law performance (i.e., engine power and efficiency).

The amount of exergy transferred with heat is shown above in Figures 13 and 14. There is a clear trend that for both additional fuels, the amount of exergy transferred with heat is more significant than gasoline. Further, the exergy transferred with heat for ethanol is slightly higher (as shown in Figure 14) than that for hydrogen. For both additional fuels, the amount of exergy transferred increases the increase in their shares. The results presented in Figure 14 help explain the increase in heat loss for ethanol compared with hydrogen.

Figure 15 shows the cylinder temperature vs. entropy inside the cylinder. This figure helps to understand the heat transfer inside the engine for the engine cycle. For the same temperature, the amount of entropy for ethanol/gasoline blends is lower than that for the $\mathrm{H}_{2}$ addition. This helps to explain the trend shown in Figures 5 for both

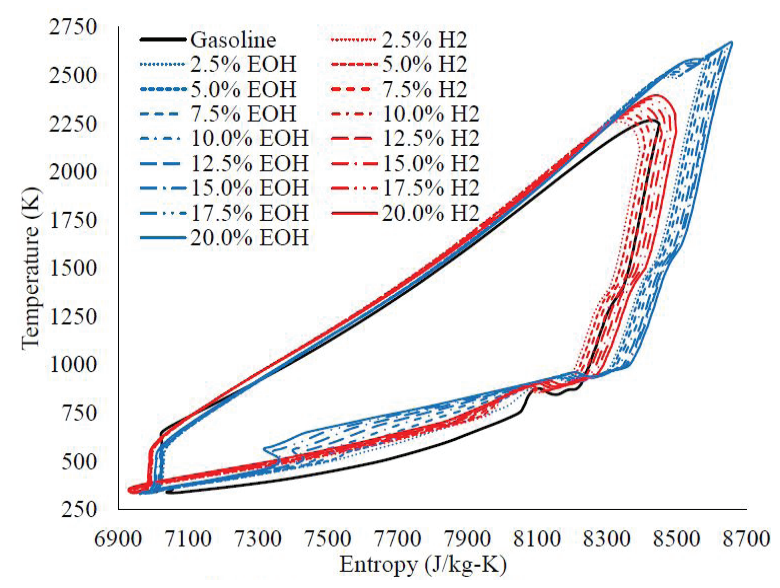

Fig. 15. Temperature-entropy diagram 
examined blends where the thermal energy losses are higher, and as a result, engine thermal efficiency drops as a result of higher heat transfer. On the other hand, the area under the curve (Figure 15) for the ethanol/gasoline blends is more significant than that for the $\mathrm{H}_{2}$ addition. This explains the trend shown in Figures 1 and 7 since the area can be understood as the total work output of the engine. Similar results are shown by [6].

\section{CONCLUSIONS}

A study on the effect of hydrogen and ethanol addition as supplementary fuel to gasoline at lean mixture $(\phi=0.8)$ was conducted. The engine performance, as well as engine emission, were calculated with the use of the first law of thermodynamics model. Further, some results of a calculation using the model based on the second law were presented.

The study clearly shows that for lean mixtures, the hydrogen addition reduced the $\mathrm{CO}$ and $\mathrm{NO}_{X}$ emission levels, compared with the ethanol addition. The hydrogen addition significantly improves the heat release rate (HRR); however, due to its fast burning nature, the heat released was close to the top dead center compared with ethanol.

The results show that the fueling of an SI engine with ethanol/gasoline and hydrogen/gasoline blends gives some benefits. The ethanol addition improves power, engine thermal efficiency, and engine availability, but hydrogen improved the engine emissions.

The research shows that $15 \%$ of hydrogen and the same ethanol share in the blends were found suitable for improving the engine performance and emissions. The influence of hydrogen in a fuel blend on the combustion process is more significant than ethanol. The research shows that for engine fueling with fuel blends, it is necessary to adjust the engine regulation parameters, especially ignition timing. It could contribute to higher engine performance and its better emissions.

\section{REFERENCES}

1. Ji C., Wang S. Effect of Hydrogen Addition On Combustion and Emissions Performance of A Spark Ignition Gasoline Engine At Lean Conditions. International journal of hydrogen energy. 2009; 34(18): 7823-7834. https://doi.org/10.1016/j. ijhydene.2009.06.082
2. Ji C., Wang S. Effect of Hydrogen Addition On the Idle Performance of A Spark Ignited Gasoline Engine At Stoichiometric Condition. International journalofhydrogenEnergy. 2009;34(8):3546-3556. https://doi.org/10.1016/j.ijhydene.2009.02.052

3. Karim G.A. Hydrogen as A Spark Ignition Engine Fuel. International Journal of Hydrogen Energy. 2003; 28(5): 569-577. https://doi.org/10.1016/ S0360-3199(02)00150-7

4. Sheet E.A.E. Performance and Sensitivity analysis of Factors Affecting NO_x Emissions from Hydrogen Fueled SI Engines. Journal of Petroleum Research \& Studies. 2016; 120(12): 47-74.

5. Verma G., Prasad R.K., Agarwal R.A., Jain S., Agarwal A.K. Experimental Investigations of Combustion, Performance and Emission Characteristics of A Hydrogen Enriched Natural Gas Fuelled Prototype Spark Ignition Engine. Fuel. 2016; 178: 209217. https://doi.org/10.1016/j.fuel.2016.03.022

6. Yamin J.A. Comparative Study Using Hydrogen and Gasoline as Fuels: Combustion Duration Effect. International Journal of Energy Research. 2006; 30(14): 1175-1187. https://doi. org/10.1002/er.1213

7. Song Y., Zheng Z., Peng T., Yang Z., Xiong W., Pei Y. Numerical Investigation of The Combustion Characteristics Of An Internal Combustion Engine With Subcritical And Supercritical Fuel. Applied Sciences. 2020; 10(3): 862. https://doi. org/10.3390/app10030862

8. Yip H.L., Srna A., Yuen A.C.Y., Kook S., Taylor R.A., Yeoh G.H., Medwell P.R., Chan Q.N. A Review of Hydrogen Direct Injection for Internal Combustion Engines: Towards Carbon-Free Combustion. Applied Sciences. 2019: 9(22): p.4842. https://doi:10.3390/app9224842

9. Shrestha S.B., Karim G.A. Hydrogen as an Additive to Methane For Spark Ignition Engine Applications. In IECEC-97 Proceedings of the Thirty-Second Intersociety Energy Conversion Engineering Conference (Cat. No. 97CH6203) 1997, Vol. 2, 910-915. https://doi: 10.1109/IECEC.1997.661890

10. Bauer C.G., Forest T.W. Effect of Hydrogen Addition on the Performance of Methane-Fueled Vehicles. Part I: Effect on SI Engine Performance. International Journal of Hydrogen Energy. 2001; 26(1): $55-70 . \quad$ https://doi.org/10.1016/S03603199(00)00067-7

11. Ma F., Ding S., Wang Y., Wang Y., Wang J., Zhao S. Study On Combustion Behaviors and Cycle-ByCycle Variations In A Turbocharged Lean Burn Natural Gas SI Engine With Hydrogen Enrichment. International Journal of Hydrogen Energy. 2008; 33(23): 7245-7255. https://doi.org/10.1016/j. ijhydene.2008.09.016

12. Ma F., Wang Y., Wang M., Liu H., Wang J., Ding S., 
Zhao S. Development and Validation of A QuasiDimensional Combustion Model For SI Engines Fuelled By HCNG With Variable Hydrogen Fractions. International journal of hydrogen energy. 2008; 33(18): 4863-4875. https://doi.org/10.1016/j. ijhydene.2008.06.068

13. Dunn-Rankin D. Lean Combustion: Technology and Control. Academic Press; 2011.

14. Veziroglu T.N. 21st Century's energy: hydrogen energy system. In Assessment of hydrogen energy for sustainable development (pp. 9-31). Springer, Dordrecht; 2007. https://doi.org/10.1007/978-14020-6442-5 2

15. Ball M., Wietschel M. The Future of HydrogenOpportunities and Challenges. International Journal of Hydrogen Energy. 2009; 34(2): 615-627. https://doi.org/10.1016/j.ijhydene.2008.11.014

16. White C.M., Steeper R.R., Lutz A.E. The Hydrogen-Fueled Internal Combustion Engine: A Technical Review. International Journal of Hydrogen Energy. 2006; 31(10): 1292-1305. https://doi. org/10.1016/j.ijhydene.2005.12.001

17. Steeper R.R., White C.M., Lutz A.E. The Hydrogen-Fueled Internal Combustion Engine: A Technical Review (No. SAND2005-3057J). Sandia National Laboratories; 2005.

18. Nakajima Y., Yamane K., Shudo T., Hiruma M., Takagi Y. Research and Development Of A Hydrogen-Fueled Engine For Hybrid Electric Vehicles. SAE transactions 2000, 1175-1179.

19. Martínez-Boggio S.D., Curto-Risso P.L., Medina A., Hernández A.C. Simulation of cycle-to-cycle variations on spark ignition engines fueled with gasoline-hydrogen blends. International Journal of Hydrogen Energy. 2016; 41(21): 9087-9099. https://doi.org/10.1016/j.ijhydene.2016.03.120

20. Kamil M., Rahman M.M. Performance prediction of spark-ignition engine running on gasoline-hydrogen and methane-hydrogen blends. Applied Energy. 2015; 158: 556-567. https://doi.org/10.1016/j. apenergy.2015.08.041

21. Akansu S.O., Tangöz S., Kahraman N., İlhak M.İ., Açıkgöz S. Experimental study of gasoline-ethanol-hydrogen blends combustion in an SI engine. International Journal of Hydrogen Energy. 2017; 42(40): 25781-25790. https://doi.org/10.1016/j. ijhydene.2017.07.014

22. D'andrea T., Henshaw P.F., Ting D.K. The Addition of Hydrogen To A Gasoline-Fuelled SI Engine. International Journal of Hydrogen Energy. 2004; 29(14): 1541-1552. https://doi.org/10.1016/j. ijhydene.2004.02.002

23. Iodice P., Langella G., Amoresano A. Ethanol In Gasoline Fuel Blends: Effect on Fuel Consumption And Engine Out Emissions Of Si Engines In Cold Operating Conditions. Applied Thermal
Engineering. 2018; 130: 1081-1089. https://doi. org/10.1016/j.applthermaleng.2017.11.090

24. Phuangwongtrakul S., Wechsatol W., Sethaput T., Suktang K., Wongwises S. Experimental study on sparking ignition engine performance for optimal mixing ratio of ethanol-gasoline blended fuels. Applied Thermal Engineering. 2016; 100: 869-879. https://doi.org/10.1016/j.applthermaleng.2016.02.084

25. Varde K.S. Combustion Characteristics of Small Spark Ignition Engines Using Hydrogen Supplemented Fuel Mixtures (No. 810921). SAE Technical Paper 1981. https://doi.org/10.4271/810921

26. Dimopoulos P., Bach C., Soltic P., Boulouchos K. Hydrogen-Natural Gas Blends Fuelling Passenger Car Engines: Combustion, Emissions and Well-ToWheels Assessment. International Journal of Hydrogen Energy. 2008; 33(23): 7224-7236. https:// doi.org/10.1016/j.ijhydene.2008.07.012

27. Ji C., Wang S., Zhang B. Combustion and Emissions Characteristics of A Hybrid Hydrogen-Gasoline Engine Under Various Loads And Lean Conditions. International Journal of Hydrogen Energy. 2010; 35(11): 5714-5722. https://doi.org/10.1016/j. ijhydene.2010.03.033

28. Wang M. The greenhouse gases, regulated emissions, and energy use in transportation (GREET) model: Version 1.5. Center for Transportation Research, Argonne National Laboratory 2008.

29. Dabas N., Dubey V., Chhabra M., Dwivedi G. Performance Analysis of an IC Engine Using Methanol, Ethanol, and Its Blend with Gasoline and Diesel as a Fuel. In Advances in Fluid and Thermal Engineering. Springer; 2019. https://doi. org/10.1007/978-981-13-6416-7_21

30. Graham L.A., Belisle S.L., Baas C.L. Emissions From Light Duty Gasoline Vehicles Operating On Low Blend Ethanol Gasoline And E85. Atmospheric Environment. 2008; 42(19): 4498-4516. https:// doi.org/10.1016/j.atmosenv.2008.01.061

31. Chao H.R., Lin T.C., Chao M.R., Chang F.H., Huang C.I., Chen C.B. Effect of MethanolContaining Additive On The Emission Of Carbonyl Compounds From A Heavy-Duty Diesel Engine. Journal of Hazardous Materials. 2000; 73(1): 39-54. https://doi.org/10.1016/S03043894(99)00162-4

32. Suarez-Bertoa R., Zardini A.A., Keuken H., Astorga C. Impact of Ethanol Containing Gasoline Blends On Emissions From A Flex-Fuel Vehicle Tested Over The Worldwide Harmonized Light Duty Test Cycle (WLTC). Fuel. 2015; 143: 173182. https://doi.org/10.1016/j.fuel.2014.10.076

33. Liu H., Wang X., Zhang D., Dong F., Liu X., Yang Y., Huang H., Wang Y., Wang Q., Zheng Z. Investigation on Blending Effects of Gasoline Fuel 
with N-Butanol, DMF, and Ethanol on the Fuel Consumption and Harmful Emissions in a GDI Vehicle. Energies 2019; 12(10): 1845. https://doi. org/10.3390/en 12101845

34. Su T., Ji C., Wang S., Cong X., Shi L. Improving The Combustion Performance Of A Gasoline Rotary Engine By Hydrogen Enrichment At Various Conditions. International Journal of Hydrogen Energy. 2018; 43(3): 1902-1908. https://doi. org/10.1016/j.ijhydene.2017.11.175

35. Yu X., Guo Z., He L., Dong W., Sun P., Du Y., Li Z., Yang H., Wang S., Wu H. Experimental Study On Lean-Burn Characteristics of An SI Engine With Hydrogen/Gasoline Combined Injection And EGR. International Journal of Hydrogen Energy. 2019; 44(26): 13988-13998. https://doi.org/10.1016/j. ijhydene.2019.03.236

36. Ratcliff M.A., Windom B., Fioroni G.M., John P.S., Burke S., Burton J., Christensen E.D., Sindler P., McCormick R.L. Impact of Ethanol Blending Into Gasoline On Aromatic Compound Evaporation And Particle Emissions From A Gasoline Direct Injection Engine. Applied Energy. 2019; 250: 1618-1631. https://doi.org/10.1016/j.apenergy.2019.05.030

37. Elfasakhany A. Exhaust Emissions and Performance Of Ternary Iso-Butanol-Bio-MethanolGasoline And N-Butanol-Bio-Ethanol-Gasoline Fuel Blends In Spark-Ignition Engines: Assessment And Comparison. Energy. 2018; 158: 830844. https://doi.org/10.1016/j.energy.2018.05.120

38. Bailey B.K. Performance of ethanol as a transportation fuel. In Handbook on Bioethanol. Routledge; 2018.

39. Ozcan H. Hydrogen Enrichment Effects On the Second Law Analysis of A Lean Burn Natural Gas Engine. International Journal of Hydrogen Energy. 2010; 35(3): 1443-1452. https://doi.org/10.1016/j. ijhydene.2009.11.039

40. Rakopoulos C.D., Kyritsis D.C. Hydrogen Enrichment Effects on the Second Law Analysis of Natural and Landfill Gas Combustion In Engine Cylinders. International Journal of Hydrogen Energy. 2006; 31(10): 1384-1393. https://doi.org/10.1016/j. ijhydene.2005.11.002

41. Rakopoulos C.D., Scott M.A., Kyritsis D.C., Giakoumis E.G. Availability Analysis of Hydrogen/Natural Gas Blends Combustion In Internal Combustion Engines. Energy. 2008; 33(2): 248-255. https:// doi.org/10.1016/j.energy.2007.05.009
42. Ghojel J.I. Review of The Development and Applications of The Wiebe Function: A Tribute to The Contribution of Ivan Wiebe To Engine Research. International Journal of Engine Research. 2010; 11(4): 297-312. https://doi. org/10.1243/14680874JER06510

43. Ferguson C.R., Kirkpatrick A.T. Internal Combustion Engines: Applied Thermosciences. John Wiley \& Sons; 2015.

44. Benson R.S. A comprehensive digital computer program to simulate a compression ignition engine including intake and exhaust systems (No. 710173). SAE Technical Paper 1971. https://doi. org/10.4271/710173

45. Caton J.A. A cycle simulation including the second law of thermodynamics for a spark-ignition engine: implications of the use of multiple-zones for combustion. SAE Transactions 2002.

46. Karagöz Y. Effect of Hydrogen Addition At Different Levels On Emissions and Performance of A Diesel Engine. Journal of Thermal Engineering. 2018; 4(2): 1780-1790.

47. Sharma P., Dhar A. Effect of hydrogen supplementation on engine performance and emissions. International Journal of Hydrogen Energy. 2018; 43(15): 75707580. https://doi.org/10.1016/j.ijhydene.2018.02.181

48. Al-Hasan M. Effect of Ethanol-Unleaded Gasoline Blends On Engine Performance and Exhaust Emission. Energy Conversion and Management. 2003; 44(9): 1547-1561.

49. Yücesu H.S., Topgül T., Cinar C., Okur M. Effect of Ethanol-Gasoline Blends On Engine Performance and Exhaust Emissions In Different Compression Ratios. Applied Thermal Engineering. 2006; 26(17-18): 2272-2278.

50. Wu C.W., Chen R.H., Pu J.Y., and Lin T.H. The Influence of Air-Fuel Ratio On Engine Performance and Pollutant Emission of An SI Engine Using Ethanol-Gasoline-Blended Fuels. Atmospheric Environment. 2004; 38(40): 7093-7100.

51. Deng X., Chen Z., Wang X., Zhen H., Xie R. Exhaust Noise, Performance and Emission Characteristics of Spark Ignition Engine Fuelled With Pure Gasoline And Hydrous Ethanol Gasoline Blends. Case Studies In Thermal Engineering. 2008; 12: 55-63.

52. Mohamad B., Szepesi G.L., Bollo B. Effect of Ethanol-Gasoline Fuel Blends on the Exhaust Emissions and Characteristics of SI Engines. In Vehicle and Automotive Engineering. Springer 2008. 